\title{
Simulated Biological Fluids with Possible Application in Dissolution Testing
}

\author{
Margareth R. C. Marques ${ }^{1, *}$, Raimar Loebenberg ${ }^{2}$, and May Almukainzi ${ }^{2}$
}

'U.S. Pharmacopeia, 12601 Twinbrook Parkway, Rockville, MD 20852, USA

${ }^{2}$ Faculty of Pharmacy and Pharmaceutical Sciences, University of Alberta, Edmonton, Alberta, Canada T6J $2 \mathrm{~L} 7$

e-mail:mrm@usp.org

\begin{abstract}
This literature review is a compilation of the composition and, in most cases, the preparation instructions for simulated biological fluids that may be used as dissolution media in the evaluation of dissolution profiles and amount of drug released from pharmaceutical dosage forms. The use of simulated biological fluids can give a better understanding of the release mechanisms and possible in vivo behavior of a product and enhance the predictive capability of the dissolution testing. A summary of the major characteristics of the most used routes of administration that may affect dissolution and absorption of drug substances is presented. The routes and simulated biological fluids covered by this review are:

- Parenteral: simulated body fluid and simulated synovial fluid.

- Oral: fasted-state simulated gastric fluid, fed-state simulated gastric fluid, fasted-state simulated intestinal fluid, fed-state simulated intestinal fluid, simulated colonic fluid, fasted-state simulated colonic fluid, and fed-state simulated colonic fluid.

- Buccal and sublingual: simulated saliva.

- Pulmonary: simulated lung fluid.

- Vaginal: simulated vaginal fluid and simulated semen.

- Ophthalmic: simulated tears.

Simulated sweat is also included. Some examples of how these simulated biological fluids are used to evaluate dosage forms are included in each route of administration.
\end{abstract}

\section{INTRODUCTION}

ntil some decades ago, most of the conventional pharmaceutical dosage forms were essentially injections, oral formulations (solutions, suspensions, tablets, and capsules), topical creams, and ointments. With the progress of drug delivery technology, novel dosage forms have been developed to overcome the problems associated with conventional drug delivery. Research has been directed toward the use of alternatives to the parenteral route for drugs that cannot be delivered orally. Potential alternative portals of drug entry to the systemic circulation include buccal, sublingual, nasal, pulmonary, and vaginal routes, among others. These routes of administration are also used for the local delivery of drugs directly to the site of action, with consequent reduction in the dose needed to produce a pharmacological effect, eliminating problems related to first-pass metabolism and possibly minimizing systemic side effects (1).

An important application of dissolution testing is the prediction of in vivo performance of pharmaceutical dosage forms. The media typically used for quality control dissolution testing do not represent all aspects of the physiological conditions of the most used routes of administration and do not allow correlation with in vivo data. Prediction of dosage form performance in the site where most of the absorption occurs requires adequate simulation of the in vivo conditions.

${ }^{*}$ Corresponding author.
This paper describes some characteristics of the parenteral, oral, buccal and sublingual, pulmonary, ophthalmic, and vaginal routes that are important to consider when developing simulated media. A compilation of the composition and preparation of several simulated biological fluids, including simulated sweat, with potential use as dissolution media is presented.

\section{PARENTERAL ROUTE}

The most used routes of injection are intramuscular, intravenous, and subcutaneous and are normally associated with short-term effects. Novel implant devices that can adequately control drug release and provide a prolonged duration of effect have been developed (1). To evaluate the in vitro drug release from these dosage forms, the dissolution medium should have ion concentrations almost equal to those of the human plasma. Table 1 describes the ionic composition of simulated body fluid (SBF) and human blood plasma. Simulated body fluid was developed initially to evaluate the surface structural changes of glass-ceramics used to manufacture artificial vertebrae, ileum, tooth roots (2), and bioactive material used to repair hard tissues such as artificial middle-ear bone and maxillofacial implants (3). This simulated body fluid was prepared using the reagents listed in Table 2. These reagents were added to $700 \mathrm{~mL}$ of water in the order given in Table 2, one by one, after each reagent was completely dissolved. The $\mathrm{pH}$ was adjusted to 7.4 with $1 \mathrm{M}$ 
Table 1. Ionic Concentration of Simulated Body Fluid and Human Blood Plasma

\begin{tabular}{|c|c|c|}
\hline Ion & $\begin{array}{l}\text { Simulated Body Fluid } \\
\qquad(\mathrm{mM})\end{array}$ & $\begin{array}{l}\text { Human Blood Plasma } \\
\text { (mM) }\end{array}$ \\
\hline $\mathrm{HCO}_{3}^{-}$ & 4.2 & 27 \\
\hline $\mathrm{K}^{+}$ & 5 & 5 \\
\hline $\mathrm{Cl}^{-}$ & 148.8 & 103 \\
\hline $\mathrm{Na}^{+}$ & 142 & 142 \\
\hline $\mathrm{Ca}^{+2}$ & 2.5 & 2.5 \\
\hline $\mathrm{Mg}^{+2}$ & 1.5 & 1.5 \\
\hline $\mathrm{HPO}_{4}^{-2}$ & 1 & 1 \\
\hline $\mathrm{SO}_{4}^{-2}$ & 0.5 & 0.5 \\
\hline $\begin{array}{l}\text { tris(hydroxymethyl) } \\
\text { aminomethane }\end{array}$ & 50 & 50 \\
\hline hydrochloric acid & 45 & 45 \\
\hline \multicolumn{3}{|l|}{ Properties } \\
\hline $\mathrm{pH}$ & 7.25 & 7.25 \\
\hline
\end{tabular}

hydrochloric acid, and the final volume adjusted to $1 \mathrm{~L}$ with water (4). In most of the studies, a volume ranging from 15 to $200 \mathrm{~mL}$ of simulated body fluid was used to evaluate the samples (2-4).

In 2003 an updated version of simulated body fluid (Table 3) with detailed instructions for its preparation was submitted to the Technical Committee ISO/TC150 of International Organization for Standardization as a solution for in vitro measurement of the apatite-forming ability of implant materials. The volume of the updated SBF to be used for sample evaluation is calculated by the formula $V_{S}=S_{a} / 10$, where $V_{s}$ is the volume of updated SBF and $S_{a}$ is the apparent surface area of the sample $\left(\mathrm{mm}^{2}\right)$.

\begin{tabular}{lc}
\hline \multicolumn{2}{l}{ Table 2. Reagents for Preparing Simulated Body Fluid } \\
\hline Reagent & Amount (g/L) \\
\hline sodium chloride & 7.996 \\
\hline sodium bicarbonate & 0.350 \\
\hline potassium chloride & 0.224 \\
\hline potassium phosphate dibasic trihydrate & 0.228 \\
\hline magnesium chloride hexahydrate & 0.305 \\
\hline 1 M hydrochloric Acid & $40 \mathrm{~mL}$ \\
\hline calcium chloride & $0.278 \mathrm{~g}$ \\
\hline sodium sulfate & 0.071 \\
\hline tris(hydroxymethyl) aminomethane & 6.057 \\
\hline
\end{tabular}

Dissolution Technologies | AUGUST 2011
Table 3. Reagents for Preparing the Updated Simulated Body Fluid

\begin{tabular}{lc}
\hline Reagent & Amount for $\mathbf{1} \mathbf{L}$ of SBF \\
\hline sodium chloride & $8.035 \mathrm{~g}$ \\
\hline sodium bicarbonate & $0.355 \mathrm{~g}$ \\
\hline potassium chloride & $0.225 \mathrm{~g}$ \\
\hline potassium phosphate dibasic trihydrate & $0.231 \mathrm{~g}$ \\
\hline magnesium chloride hexahydrate & $0.311 \mathrm{~g}$ \\
\hline 1 M hydrochloric acid & $39 \mathrm{~mL}$ \\
\hline calcium chloride & $0.292 \mathrm{~g}$ \\
\hline sodium sulfate & $0.072 \mathrm{~g}$ \\
\hline tris(hydroxymethyl) aminomethane & $6.118 \mathrm{~g}$ \\
\hline
\end{tabular}

For porous materials, the volume of SBF should be greater than the calculated $V_{\mathrm{S}}(5)$.

Radiation synovectomy is one of the ways to treat rheumatoid arthritis. This technique involves intra-articular injection of radioactive particles. An ideal particulate system for radiation synovectomy would contain a pure beta-emitting radioisotope and would be biodegradable. Currently radiocolloids and tagged macroaggregates are the preferred systems. Radiocolloids are composed of nanosized radioisotopes in resin, silicate, or citrate form. Tagged macroaggregates are much larger than radiocolloids and are formed when a substance is precipitated in a solution containing a radioactive isotope; one example is ferric hydroxide macroaggregates tagged with ${ }^{165} \mathrm{Dy}$ (dysprosium). Conzone et al. $(6,7)$ evaluated the in vitro dissolution of dysprosium lithium borate microspheres using simulated synovial fluid (Table 4).

If the solution is prepared with only the first four reagents, it is known as phosphate buffered saline solution (PBS). Hyaluronic acid is a mucopolysaccharide and is the primary diffuse macromolecule that exists in human

\begin{tabular}{lc}
\hline Table 4. Simulated Synovial Fluid & \\
\hline Reagent & Amount (g/L) \\
\hline sodium chloride & 8 \\
\hline potassium chloride & 0.2 \\
\hline sodium phosphate dibasic & 1.44 \\
\hline potassium phosphate monobasic & 0.24 \\
\hline hyaluronic acid & 3 \\
\hline Properties & 7.4 \\
\hline pH
\end{tabular}


synovial fluid. A volume ranging from 10 to $20 \mathrm{~mL}$ of this simulated fluid was used in the in vitro tests $(6,7)$.

The synovial fluid was used to evaluate the in vitro bioactive behavior (in vitro bone-bonding ability) of tissue-engineered osteochondral (bone-cartilage) composite used in the treatment of lesions of the articular cartilage. The simulated synovial fluid was continuously circulated in physiological conditions ( $\mathrm{pH} 7.4$ and $37^{\circ} \mathrm{C}$ ) using a peristaltic pump for up to 14 days with an available volume of $50 \mathrm{~mL}$ of fluid (8).

\section{ORAL ROUTE}

The oral route is the most common and convenient administration method for the systemic delivery of drugs. It affords high patient-acceptability, compliance, and ease of administration. Moreover, the cost of oral therapy is generally much lower than that of parenteral therapy (1).

Nevertheless, the oral route is not without disadvantages, particularly with respect to labile drugs such as peptide- and oligonucleotide-based pharmaceuticals. During the last decades, numerous novel oral drug delivery systems such as mucoadhesives, matrix systems, reservoir systems, microparticulates, and colon-specific drug delivery systems have been developed to overcome some of these limitations (1).

The $\mathrm{pH}$ of the fluids in the fasted-state stomach is typically below 2, but can range between 1 and 7.5. Food intake results in an almost instantaneous increase of the gastric $\mathrm{pH}$. Depending on the contents of the meal, the fed-state gastric $\mathrm{pH}$ increases to values between 4 and 7 . Soon after food intake, the gastric $\mathrm{pH}$ gradually returns to the fasted-state $\mathrm{pH}$. Determinations of the fasted-state $\mathrm{pH}$ in the proximal small intestine often result in mean values of approximately 6.5 , but can fluctuate momentarily between 2 and 7. Prior to emptying of the stomach content into the small intestine, the duodenal $\mathrm{pH}$ is in the fasted-state range (i.e., approximately 6.5). Postprandially, the $\mathrm{pH}$ in this region gradually decreases as increasingly acidic gastric content enters the intestine, before returning to fasted-state values at the completion of the digestive period. In the distal small intestine (ileum), the $\mathrm{pH}$ rises to approximately 7.5 because of bicarbonate secretion. Furthermore, the effect of food intake on $\mathrm{pH}$ diminishes toward the distal end of the small intestine. Because of the formation of short-chain fatty acids by fermentation, the $\mathrm{pH}$ falls considerably from the terminal ileum to the ascending colon. Some studies show that the $\mathrm{pH}$ in the caecum/ascending colon is on average just over 6, but values between 5.7 and 8.4 have also been reported. The short-chain fatty acids are quickly absorbed and metabolized during transit through the proximal colon, and together with bicarbonate secretion, result in an increase in the luminal $\mathrm{pH}$ toward the distal colon. The rare observations of $\mathrm{pH}$ in the descending colon/rectum point toward a value closer to 7 (9).

Drug absorption may be affected by several physiological factors including volume and composition of

\begin{tabular}{|c|c|c|c|c|}
\hline \multirow[b]{2}{*}{ Composition } & \multirow[b]{2}{*}{ FaSSGF } & \multicolumn{3}{|c|}{ FeSSGF } \\
\hline & & Early & Middle & Late \\
\hline sodium taurocholate $(\mu \mathrm{M})$ & 80 & - & - & - \\
\hline lecithin $(\mu \mathrm{M})$ & 20 & - & - & - \\
\hline pepsin $(\mathrm{mg} / \mathrm{mL})$ & 0.1 & - & - & - \\
\hline sodium chloride (mM) & 34.2 & 148 & 237.02 & 122.6 \\
\hline acetic acid (mM) & - & - & 17.12 & - \\
\hline sodium acetate (mM) & - & - & 29.75 & - \\
\hline orthophosphoric acid (mM) & - & - & - & 5.5 \\
\hline $\begin{array}{l}\text { sodium diyhydrogen } \\
\text { phosphate }\end{array}$ & - & - & - & 32 \\
\hline milk/buffer & - & $1: 0$ & $1: 1$ & $1: 3$ \\
\hline $\begin{array}{l}\text { hydrochloric acid/sodium } \\
\text { hydroxide q.s. }\end{array}$ & $\mathrm{pH} 1.6$ & $\mathrm{pH} 6.4$ & $\mathrm{pH} 5$ & $\mathrm{pH} 3$ \\
\hline Properties & & & & \\
\hline $\mathrm{pH}$ & 1.6 & 6.4 & 5 & 3 \\
\hline osmolality (mOsm/kg) & $\begin{array}{l}120.7 \pm \\
2.5\end{array}$ & 559 & 400 & 300 \\
\hline buffer capacity (mmol/L/pH) & - & 21.33 & 25 & 25 \\
\hline surface tension (mN/m) & 42.6 & - & - & - \\
\hline
\end{tabular}

gastrointestinal fluids, the $\mathrm{pH}$ and buffer capacity of these fluids, digestive enzymes, contraction patterns, and bacterial flora in the gut. In addition, the extent of drug absorption and bioavailability may be further affected by gastrointestinal transit, the presence of cellular transporters, and metabolic enzymes. Several of those factors are affected by intake of food. The effects of food on the physiology and consequently on the in vivo drug release and absorption are most pronounced in the stomach. In fact, even coadministration of water with a dosage form may influence the conditions in the stomach because of dilution effects (9). The oral bioavailability of many, but not all, drugs is affected by food intake. The absorption of a drug can be increased, decreased, delayed, or accelerated depending not only on the physicochemical characteristics of the drug substance but also on the type of dosage form, composition of the ingested food, and general state of the gastrointestinal tract (10).

\section{Simulated Gastric Fluids}

Vertzoni et al. (11) developed a simulated gastric medium that more adequately reflects the physiological conditions of the fasted state (see FaSSGF, fasted-state simulated gastric fluid in Table 5). This medium contains pepsin and low amounts of bile salt and lecithin. The 


\begin{tabular}{lc}
\hline \multicolumn{2}{l}{ Table 6. Fasted-State Simulated Intestinal Fluid (FaSSIF) } \\
\hline \multicolumn{1}{l}{ Composition } & FaSSIF \\
\hline sodium taurocholate $(\mathrm{mM})$ & 3 \\
\hline lecithin $(\mathrm{mM})$ & 0.2 \\
\hline maleic Acid $(\mathrm{mM})$ & 19.12 \\
\hline sodium hydroxide $(\mathrm{mM})$ & 34.8 \\
\hline sodium chloride $(\mathrm{mM})$ & 68.62 \\
\hline Properties & 6.5 \\
\hline pH & $180 \pm 10$ \\
\hline osmolality $(\mathrm{mOsm} / \mathrm{kg})$ & 10 \\
\hline buffer capacity $(\mathrm{mmol} / \mathrm{L} / \mathrm{pH})$ & \\
\hline
\end{tabular}

reduced surface tension of this medium is created by a mixture of pepsin, bile salts, and lecithin (11).

A major issue when trying to simulate the intragastric environment in the fed state is the composition change with time as digestion proceeds and emptying occurs. Media that simulate the initial composition after food intake include full-fat milk (3.5\%), which simulates a light meal, and Ensure Plus, which has physicochemical properties that are similar to those of the standard meal recommended by FDA for the effects of food in bioavailability and bioequivalence studies (12). One way of modeling composition changes is to develop "snapshot" media, each corresponding to a certain time after ingestion of the meal. It has been suggested that the most suitable medium representing the fed-state stomach is the homogenized form of the meal used in clinical studies, but difficulties in the analysis of the drug released into the medium put some limitations on its use (13). The composition of each snapshot medium was calculated to reflect the $\mathrm{pH}$ value, buffer capacity, and osmolality of the gastric aspirates during the first $75 \mathrm{~min}$ (early), from 75 to $165 \mathrm{~min}$ (middle), and 165 min (late) after meal ingestion (see FeSSGF, fed-state simulated gastric fluid, Table 5) $(13,14)$.

\section{Simulated Intestinal Fluids}

Biorelevant media simulating preprandial and postprandial conditions in the upper small intestine, including fasted-state simulated intestinal fluid (FaSSIF) and fedstate simulated intestinal fluid (FeSSIF), were introduced some years ago. These media were intended to simulate additional important aspects of the Gl fluids, including bile salts and lecithin. Some adjustments to these media have been made to improve predictions of in vivo performance. From studies in healthy human volunteers, it was verified that the concentrations of bile salts observed in vivo are somewhat lower than in FeSSIF. The original FeSSIF contained no lipolysis products, which together with the bile can enhance the solubility of poorly soluble drugs.

\begin{tabular}{|c|c|c|c|c|}
\hline \multirow[b]{2}{*}{ Composition } & \multicolumn{3}{|c|}{ FeSSIF } & \multirow[b]{2}{*}{ FeSSIF-V2 } \\
\hline & Early & Middle & Late & \\
\hline $\begin{array}{l}\text { sodium taurocholate } \\
\text { (mM) }\end{array}$ & 10 & 7.5 & 4.5 & 10 \\
\hline lecithin (mM) & 3 & 2 & 0.5 & 2 \\
\hline maleic acid (mM) & 28.6 & 44 & 58.09 & 55.02 \\
\hline $\begin{array}{l}\text { sodium hydroxide } \\
\text { (mM) }\end{array}$ & 52.5 & 65.3 & 72 & 81.65 \\
\hline $\begin{array}{l}\text { sodium chloride } \\
\text { (mM) }\end{array}$ & 145.2 & 122.8 & 51 & 125.5 \\
\hline $\begin{array}{l}\text { glyceryl monocho- } \\
\text { late (mM) }\end{array}$ & 6.5 & 5 & 1 & 5 \\
\hline sodium oleate (mM) & 40 & 30 & 0.8 & 0.8 \\
\hline \multicolumn{5}{|l|}{ Properties } \\
\hline $\mathrm{pH}$ & 6.5 & 5.8 & 5.4 & 5.8 \\
\hline $\begin{array}{l}\text { osmolality } \\
\text { (mOsm/kg) }\end{array}$ & $400 \pm 10$ & $390 \pm 10$ & $240 \pm 10$ & $390 \pm 10$ \\
\hline $\begin{array}{l}\text { buffer capacity } \\
(\mathrm{mmol} / \mathrm{L} / \mathrm{pH})\end{array}$ & 25 & 25 & 15 & 25 \\
\hline
\end{tabular}

Additionally, recent data in humans indicate that the $\mathrm{pH}$ in the upper small intestine decreases rather slowly after meal intake (Table 6) $(13,14)$.

As for the gastric fluids, the composition of the intestinal fluids changes over time in the fed state. Three snapshot media were developed to reflect conditions in the upper small intestine during the digestion process (see FeSSIF in Table 7) $(13,14)$.

As with the gastric media, it is practical to select compositions that globally reflect conditions in the upper small intestine before and after meals for the purposes of comparing formulations or assessing food effects. For the fasted state, FaSSIF (Table 5) is suitable. For the fed state, an improved composition was developed (see FeSSIF-V2 in Table 6) $(13,14)$.

The volume of fluids in the fasted stomach is usually only about $30-50 \mathrm{~mL}$. Considering the coadministered fluid ( $250 \mathrm{~mL}$, as standardized in most in vivo studies), the final volume is around $300 \mathrm{~mL}$. Therefore, a realistic volume to simulate the total fluid available in the stomach in the fasted state would fall in the range of $250-300 \mathrm{~mL}$. To evaluate drug release in this volume, the use of USP Apparatus 3 or mini-vessels may be appropriate. Because the minimum volume of medium that can be used with USP Apparatus 2 (paddles) is slightly higher than $300 \mathrm{~mL}$ (otherwise the paddle is not completely immersed in the medium), a volume of $500 \mathrm{~mL}$ is recommended. To simulate fasted conditions in the small intestine, a volume of up to $200 \mathrm{~mL}$ would be appropriate. Volumes of up to 


\begin{tabular}{lc}
\hline \multicolumn{1}{l}{ Table 8. Simulated Colonic Fluid 1 (SCoF1) } \\
\hline Composition & Amount (g/L) \\
\hline potassium chloride & 0.20 \\
\hline sodium chloride & 8 \\
\hline potassium phosphate monobasic & 0.24 \\
\hline sodium phosphate dibasic & 1.44 \\
\hline Properties & \\
\hline pH & 7 \\
\hline
\end{tabular}

one liter would be recommended for the fed-state small intestine (11-14).

The preparation of these simulated fluids is time consuming, requires organic solvents, makes daily preparation necessary, and sometimes does not result in a usable medium. The possible residual organic solvents may affect physicochemical properties and dissolution behavior. One way of reducing or eliminating these problems is to use a simplified method for preparation of the media mentioned in Tables 3, 4, and 5, which can be found in the literature (15), or use freeze-drying methods for bulk preparation of storable, instant media (16).

Use of FaSSIF and FeSSIF as the apical media in Caco-2 permeation studies may improve the biorelevance of the model to evaluate the oral absorption in humans (17). The composition of these media may be modified for more compatibility with Caco-2 cells (18).

\section{Simulated Colonic Fluid (SCoF)}

A major indication for colon-specific drug delivery is in the treatment of local disorders of the colon, such as inflammatory bowel disease (IBD, which includes ulcerative colitis and Crohn's disease) and carcinoma of the colon. The colon can also be used as an absorption site for the delivery of drugs to the systemic circulation. Although absorption from the colon is generally much lower than from the small intestine, systemic drug delivery via the colon has some advantages such as prolonged residence time, relatively low enzyme secretion, and delivery directly into the systemic circulation, avoiding hepatic first-pass effect (1).

Recently, there has been increasing interest in targeting peptide and protein drugs to the colon because of the relatively low activity of proteolytic enzymes in the colon. One of the possible platforms for targeted drug delivery to the colon is to modify the structure of starch to improve its resistance to digestion. This prevents enzymatic digestion and acidolysis in the upper digestive tracts but subjects it to degradation by microorganisms in the colon. These modified starches are known as enzyme-resistant starches. Chen et al. (19) evaluated the in vitro release of bovine serum albumin from matrixes made of these modified starches using the SCoF1 described in Table 8.

\begin{tabular}{lc}
\hline \multicolumn{2}{l}{ Table 9. Simulated Colonic Fluid 2 (SCoF2) } \\
\hline Composition & Concentration (mM) \\
\hline acetic acid & 170 \\
\hline sodium hydroxide & $\sim 157$ \\
\hline Properties & 5.8 \\
\hline pH & 295 \\
\hline osmolality (mOsmol/kg) & 29.1 \\
\hline buffer capacity $(\mathrm{mEq} / \mathrm{L} / \mathrm{pH})$ & 0.16 \\
\hline ionic strength & \\
\hline
\end{tabular}

The in vitro release of metronidazole from modified Pulsincap dosage forms targeted to the colon in a timedependent manner was evaluated using $\mathrm{pH} 6.8$ phosphate buffer (20). The same buffer was used in the in vitro evaluation of colon-specific formulations for orally administered diclofenac sodium (21). Pectinolytic enzyme was added to $\mathrm{pH} 6.8$ phosphate buffer to assess the in vitro drug-release behavior of pectin cross-linked with glutaraldehyde nanogel particles, a matrix for colonic drug delivery (22).

The $\mathrm{pH}$ in the initial part of the large intestine has been reported to range with time and composition of food intake from 4.8 to 7 . In this location, enzymes produced by bacteria metabolize several residual nutrients.

Carbohydrates and proteins are broken down during bacterial fermentation to short-chain fatty acids, ammonia, hydrogen, carbon dioxide, and sometimes methane. Acetate, propionate, and butyrate are the principal organic anions found in colonic contents. The average concentration of total short-chain fatty acids in the ascending colon has been reported as 120-130 mM. Further, about 1-1.5 L of a nearly isotonic fluid enters the colon daily. Most of the fluid is absorbed, so the volume excreted in feces is only about 50-200 mL. With regard to electrolytes, short-chain fatty acids stimulate absorption of sodium and water, whereas chloride is absorbed in exchange for bicarbonate (secreted to neutralize the organic acids produced). Based on these observations, Fotaki et al. (23) developed a fluid to simulate the contents of the proximal colon (Table 9). This medium was used to predict the input profiles of extended-release products containing isosorbide-5mononitrate.

Recently, Vertzoni et al. (24) developed media simulating the physicochemical characteristics of the ascending colon in the fasted and fed states.

\section{Fasted-State Simulated Colonic Fluid (FaSSCoF)}

Tris/maleate buffer solution is prepared by dissolving $5.5 \mathrm{~g}$ of tris(hydroxymethyl) aminomethane (Tris) and 8.8 $\mathrm{g}$ of maleic acid in water. The $\mathrm{pH}$ is adjusted to 7.8 with about $240 \mathrm{~mL}$ of $0.5 \mathrm{M}$ sodium hydroxide, and the final volume is adjusted to $1 \mathrm{~L}$ with water. About $450 \mathrm{~mL}$ of this 
solution is transferred to a 1-L round-bottom flask, and $0.113 \mathrm{~g}$ of bile salt extract is added. Two separate solutions are prepared by dissolving $0.222 \mathrm{~g}$ of phosphatidylcholine and $0.026 \mathrm{~g}$ of palmitic acid separately in $3 \mathrm{~mL}$ of dichloromethane each. These two solutions ( $3 \mathrm{~mL}$ each) are transferred into the round-bottom flask. The dichloromethane is evaporated under vacuum at $40{ }^{\circ} \mathrm{C}$ until a clear solution having no perceptible odor of dichloromethane is obtained. The volume of the solution is adjusted to $1 \mathrm{~L}$ with tris/maleate buffer, and $3 \mathrm{~g}$ of bovine serum albumin are added and dissolved by gentle agitation with a magnetic stirrer. The final solution is lightly turbid. The $\mathrm{pH}$ of this medium is about 7.8.

\section{Fed-State Simulated Colonic Fluid (FeSSCoF)}

Tris/maleate buffer solution is prepared by dissolving $3.7 \mathrm{~g}$ of tris(hydroxymethyl) aminomethane (Tris) and 3.5 $\mathrm{g}$ of maleic acid in water. The $\mathrm{pH}$ is adjusted to 6.0 with about $33 \mathrm{~mL}$ of $0.5 \mathrm{M}$ sodium hydroxide, and the final volume is adjusted to $1 \mathrm{~L}$ with water. About $450 \mathrm{~mL}$ of this solution is transferred to a $1-\mathrm{L}$ round-bottom flask, and $0.451 \mathrm{~g}$ of bile salt extract is added. Two separate solutions are prepared by dissolving $0.370 \mathrm{~g}$ of phosphatidylcholine and $0.051 \mathrm{~g}$ of palmitic acid separately in $3 \mathrm{~mL}$ of dichloromethane each. These two solutions ( $3 \mathrm{~mL}$ each) are transferred into the round-bottom flask. The dichloromethane is evaporated under vacuum at $40^{\circ} \mathrm{C}$ until a clear solution having no perceptible odor of dichloromethane is obtained. The volume of the solution is adjusted to $1 \mathrm{~L}$ with tris/maleate buffer, and $2 \mathrm{~g}$ of sodium chloride, $14 \mathrm{~g}$ of glucose, and $3 \mathrm{~g}$ of bovine serum albumin are added and dissolved by gentle agitation with a magnetic stirrer. The final solution is lightly turbid. The $\mathrm{pH}$ of this medium is about 6.0 .

\section{BUCCAL AND SUBLINGUAL ROUTE}

Localized drug delivery to the mouth is used for the treatment of conditions of the oral cavity, principally aphthous ulcers, fungal conditions, and periodontal disease. However, in addition to topical delivery, there has been considerable interest in the possibility of oral transmucosal delivery to achieve the systemic delivery of drug moieties via the mucous membranes of the oral cavity. Oral transmucosal drug delivery can be subdivided into (1) sublingual, via the mucosa of the ventral surface of the tongue and the floor of the mouth under the tongue; and (2) buccal, via the buccal mucosa, the epithelial lining of the cheeks, the gums, and also the upper and lower lips (1). Drugs absorbed here are not exposed to gastrointestinal secretions that may cause degradation. Moreover, they bypass the liver in the first circulatory pass and are not exposed to microsomal enzymes before entering the general circulation, as is usually the case in gastrointestinal absorption $(25,26)$.

It is almost impossible to duplicate the properties of human saliva because of its particular characteristics.
Saliva is a mixture of fluids secreted by several salivary glands, it is a system with numerous constituents, and it is variable according to the time of day, diet, and so forth (27). The dilution and rapid elimination of the drugs from the oral cavity are consequences of speech, mastication, and continuous saliva production. Normal, healthy saliva in the oral cavity has a pH between 6.7 and 7.4, but it can temporarily drop below 5 when sweets, carbonated and fruit drinks, and other dietary acids are consumed. Some drugs, such as beta blocking agents, nitrates, and diuretics, as well as tobacco smoking can also reduce salivary $\mathrm{pH}(28)$.

Duffo and Castillo (27) developed an artificial saliva (SS1 in Table 10) for studying the corrosion behavior of dental alloys. In this solution, all components dissolve completely. It is recommended to add potassium bicarbonate just before use to avoid loss of $\mathrm{CO}_{2}$ and changes in the $\mathrm{pH}$. Bicarbonate is the major buffering agent of saliva, and is readily lost on standing when exposed to the air. This loss is the principal, if not the sole, cause of rise in $\mathrm{pH}$ that is observed on short-term standing. SS1 can be stored at $5{ }^{\circ} \mathrm{C}$ for at least 8 days without modification of its properties.

SS2 was used to develop computational models to predict local effects on the mouth from carcinogenic compounds present in tobacco smoke (28).

The interaction of benzethonium-copolymer complex, used in mouth rinse or dentifrices, was evaluated using SS3 (29).

Davis et al. (25) used SS4 in a dynamic dialysis system to investigate the interactions that might occur between drug molecules and the constituents of salivary secretions. Such interactions, if they occur, might influence drug absorption through the oral mucosa.

SS $5(300 \mathrm{~mL})$ was used to monitor the release of salbutamol sulphate from oral fast-dissolving films using USP Apparatus 2 (paddles) $(30,31)$.

\section{PULMONARY ROUTE}

Pulmonary drug delivery is used primarily to treat conditions of the airways, delivering locally acting drugs directly to their site of action. The lung may also be employed as a route for delivery of drugs into the systemic circulation and onward to an effect site located elsewhere in the body.

Mucus does not exist in the alveolar region, but is present as a viscoelastic layer in the tracheobronchial region. Respiratory mucus is a complex mixture that includes glycoproteins, proteins, and lipids. Its composition is also highly variable in disease states, with infections being accompanied by high levels of DNA.

Epithelial type-II cells constantly secrete and reutilize lung surfactant. It consists of lipid-rich lipoproteins with the lipid composition dominated by phosphatidylcholine with a high dipalmitoyl content. About $85-90 \%$ of isolated surfactant is lipid of which $95 \%$ is phosphoglycerols with cholesterol as the main neutral component. Many proteins 


\begin{tabular}{|c|c|c|c|c|c|}
\hline Composition & SS 1 (g/L) & SS 2 (g/L) & SS 3 (g/L) & SS 4 (g/L) & SS 5 (g/L) \\
\hline potassium chloride & 0.720 & 0.720 & - & 0.149 & \\
\hline calcium chloride dihydrate & 0.220 & 0.220 & 0.228 & - & \\
\hline sodium chloride & 0.600 & 0.600 & 1.017 & 0.117 & 8.00 \\
\hline potassium phosphate monobasic & 0.680 & 0.680 & - & - & 0.19 \\
\hline sodium phosphate dibasic & $\begin{array}{c}0.866 \\
\text { (dodecahydrate) }\end{array}$ & $\begin{array}{c}0.866 \\
\text { (dodecahydrate) }\end{array}$ & $\begin{array}{c}0.204 \\
\text { (heptahydrate) }\end{array}$ & - & 2.38 \\
\hline potassium bicarbonate & 1.500 & 1.500 & - & - & \\
\hline potassium thiocyanate & 0.060 & 0.060 & - & - & \\
\hline citric Acid & 0.030 & 0.030 & - & - & \\
\hline magnesium chloride hexahydrate & - & - & 0.061 & - & \\
\hline potassium carbonate hemihydrate & - & - & 0.603 & - & \\
\hline $\begin{array}{l}\text { sodium phosphate monobasic } \\
\text { monohydrate }\end{array}$ & - & - & 0.273 & - & \\
\hline sodium bicarbonate & - & - & - & 2.100 & \\
\hline submaxillary mucin & - & - & 1.000 & - & \\
\hline alpha-amylase & - & - & 2.000 & 2.000 & \\
\hline mucin gastric & - & - & - & 1.000 & \\
\hline \multicolumn{6}{|l|}{ Properties } \\
\hline $\mathrm{pH}$ & 6.5 & 7.4 & - & - & 6.8 \\
\hline
\end{tabular}

are also present, and in addition to albumin, which might be a contaminant, include four non-serum apoproteins (SP-A, SP-B, SP-C and SP-D) (1).

Table 11 lists some of the most used simulated lung fluids (SLF). SLF1 has been used to evaluate human exposure to particulates from environmental emissions. Artificial lysosomal fluid (ALF) and Gamble's solution were used to simulate different interstitial conditions in the lung. ALF is analogous to the fluid with which inhaled particles would come into contact after phagocytosis by alveolar and interstitial macrophages in the lung. Gamble's solution represents the interstitial fluid deep within the lung. When preparing Gamble's solution, the components should be added in the order presented in Table A to avoid salt precipitation. Citrate was used instead of proteins to avoid foaming and acetate instead of organic acids. Gamble's solution has a pH of 7.4, whereas ALF has a $\mathrm{pH}$ of 4.5 and has a much higher organic content than Gamble's solution (32).

SLF2 is a modified version of Gamble's solution; it was used to estimate potential human exposure to $\mathrm{Hg}$ due to inhalation of airborne calcine particulates from mine waste. This simulated fluid was designed to model interactions of particles with extracellular lung fluids (33).
SLF3 models the interstitial fluid (ionic equivalent amount of citrate used to replace protein because of foaming). Care must be taken in mixing the components to prevent precipitation. The starting volume of water should be at least $95 \%$ of the desired final volume; otherwise, a precipitate may form when some compounds are added (34). This simulated fluid was used to evaluate the in vitro release of insulin from poly(lactide-co-glycolide) (PLGA)/cyclodextrin porous particles intended for pulmonary delivery of insulin (35).

Designing a standardized dissolution method applicable to the lung is not an easy task, because the lung has unique features that are difficult to replicate in vitro, such as the extremely small amount of aqueous fluid and lung surfactant. Son and McConville (36) described a potential standardized test method to characterize the dissolution properties of a multitude of formulation types available for pulmonary delivery. SLF3 and SLF4 (SLF3 modified with the addition of $0.02 \%$ [w/v] dipalmitoylphosphatidylcholine [DPPC]) were used. To prepare SLF4, $200 \mathrm{mg}$ of DPPC was weighed into a $500-\mathrm{mL}$ round-bottom flask and dissolved in $40 \mathrm{~mL}$ of a mixture of chloroform and methanol (1:1). The solvent was evaporated using a rotary evaporator. The dry film was dissolved with $200 \mathrm{~mL}$ of 
Table 11. Simulated Lung Fluid (SLF)

\begin{tabular}{|c|c|c|c|c|c|c|}
\hline \multirow[b]{2}{*}{ Composition } & \multicolumn{2}{|r|}{ SLF1 } & \multirow{2}{*}{$\begin{array}{c}\text { SLF2 } \\
(\mathrm{mg} / \mathrm{L})\end{array}$} & \multirow{2}{*}{$\frac{\text { SLF3 }}{(g / L)}$} & \multirow{2}{*}{$\begin{array}{l}\text { SLF4 } \\
(g / L)\end{array}$} & \multirow{2}{*}{$\begin{array}{c}\text { SLF5 } \\
\mathrm{mMol} / \mathrm{L}\end{array}$} \\
\hline & ALF (g/L) & Gamble's Solution (g/L) & & & & \\
\hline magnesium chloride & 0.050 & 0.095 & - & $\begin{array}{c}0.2033 \\
\text { (hexahydrate) }\end{array}$ & $\begin{array}{c}\mathrm{MgCl}_{2} \\
\text { hexahydrate } \\
0.2033\end{array}$ & - \\
\hline sodium chloride & 3.21 & 6.019 & 6800 & 6.0193 & 6.0193 & 116 \\
\hline potassium chloride & - & 0.298 & - & 0.2982 & 0.2982 & - \\
\hline $\begin{array}{l}\text { disodium hydrogen phos- } \\
\text { phate }\left(\mathrm{Na}_{2} \mathrm{HPO}_{4}\right)\end{array}$ & 0.071 & 0.126 & $\begin{array}{c}1700 \\
\text { (monohydrate) }\end{array}$ & - & - & - \\
\hline sodium sulfate & 0.039 & 0.063 & - & $\begin{array}{c}0.0710 \\
\text { (anhydrous) }\end{array}$ & $\begin{array}{c}0.0710 \\
\text { (anhydrous) }\end{array}$ & - \\
\hline calcium chloride dihydrate & 0.128 & 0.368 & 290 & 0.3676 & 0.3676 & 0.2 \\
\hline sodium acetate & - & 0.574 & 580 & $\begin{array}{c}0.9526 \\
\text { (trihydrate) }\end{array}$ & $\begin{array}{c}0.9526 \\
\text { (trihydrate) }\end{array}$ & - \\
\hline $\begin{array}{l}\text { sodium hydrogen carbonate } \\
\left(\mathrm{NaHCO}_{3}\right)\end{array}$ & - & 2.604 & 2300 & 2.6043 & 2.6043 & 27 \\
\hline sodium citrate dihydrate & 0.077 & 0.097 & - & 0.0970 & 0.0970 & 0.2 \\
\hline sodium hydroxide & 6.00 & - & - & - & - & - \\
\hline citric acid & 20.8 & - & $\begin{array}{c}420 \\
\text { (monohydrate) }\end{array}$ & - & - & - \\
\hline glycine & 0.059 & - & 450 & - & - & 5 \\
\hline sodium tartrate dihydrate & 0.090 & - & - & - & - & - \\
\hline sodium lactate & 0.085 & - & - & - & - & - \\
\hline sodium pyruvate & 0.086 & - & - & - & - & - \\
\hline ammonium chloride & - & - & 5300 & - & - & 10 \\
\hline phosphoric Acid & - & - & 1200 & - & - & - \\
\hline sodium carbonate & - & - & 630 & - & - & - \\
\hline potassium acid phthalate & - & - & 200 & - & - & - \\
\hline sulfuric acid & - & - & 510 & - & - & 0.5 \\
\hline sodium citrate dihydrate & - & - & 590 & - & - & - \\
\hline $\begin{array}{l}\text { sodium phosphate monobasic } \\
\text { monohydrate }\end{array}$ & - & - & - & 0.1420 & 0.1420 & 1.2 \\
\hline L-cystine hydrochloride & - & - & - & - & - & 1.0 \\
\hline $\mathrm{DPPC}^{a}$ & - & - & - & - & $0.02 \%(w / v)$ & - \\
\hline DTPA $^{b}$ & - & - & - & - & - & 0.2 \\
\hline $\mathrm{ABDCB}^{\mathrm{c}}$ & - & - & - & - & - & 50 \\
\hline Properties & & & & & & \\
\hline $\mathrm{pH}$ & 4.5 & 7.4 & 7.4 & 7.4 & 7.4 & - \\
\hline
\end{tabular}

${ }^{a} D P P C$ : dipalmitoylphosphatidylcholine.

${ }^{b} D T P A$ : diethylenetriaminepentaacetic acid.

'ABDCB: alkylbenzyl dimethyl ammonium chloride $50 \%$ by volume. 
water at $55^{\circ} \mathrm{C}$ and agitated for $2 \mathrm{~h}$. The warm suspension was sonicated at $55^{\circ} \mathrm{C}$ for $1 \mathrm{~h}$. The concentrated DPPC solution was stored at $4{ }^{\circ} \mathrm{C}$ and diluted with SLF3 before use. SLF4 was used to evaluate the in vitro release of itraconazole from nebulized nanoparticle dispersions (37).

Cheng et al. (38) used SLF5 to evaluate the dissolution of titanium tritide particles used as components of neutron generators. These particles may be released into the air as aerosols during fabrication, assembling, and testing of components or in accidental or fugitive releases.

\section{VAGINAL ROUTE}

Until recently, vaginal preparations on the market were restricted to those that were topically effective for localized treatment of a variety of conditions. Current technologies in vaginal drug delivery are concerned with the systemic delivery of drugs such as estrogens, progesterones, and prostaglandins. New technologies explore the systemic delivery of therapeutic peptides and proteins via the vaginal route, for example.

Although the vaginal epithelium is relatively aglandular (in comparison with other possible delivery sites such as the gastrointestinal tract), it is usually covered with a surface film of moisture, "the vaginal fluid."The vaginal fluid is composed of cervical fluid (the vagina receives approximately $2 \mathrm{~g}$ of mucus per day from the cervix) and small amounts of the secretion from Bartholin's glands in the vaginal wall. The vaginal secretions, which serve as a protective barrier for infections, contain a variety of antimicrobial substances including lysozyme, lactoferrin, fibronectin, polyamines such as spermine, and secretory $\lg A$. The fluids also contain carbohydrate from the epithelial glycogen, amino acids, aliphatic acids, and proteins.

The bioavailability of drugs administered via the vaginal route depends on both the effective dissolution of solid drug particles, if present, in the vaginal fluid prior to absorption and the degree of deactivation by enzymes present in the fluids.

The $\mathrm{pH}$ in the vaginal lumen is controlled primarily by lactic acid produced from cellular glycogen, or by carbohydrates produced by the action of the normal vaginal microflora. Vaginal $\mathrm{pH}$ in an adult female varies between 4.0 and 5.0, depending on the particular stage of the menstrual cycle. During pregnancy, the $\mathrm{pH}$ is lower and varies between 3.8 and 4.4 (due to an increase in cellular glycogen content); in the postmenopausal state or after oophorectomy, the $\mathrm{pH}$ increases to 7.0-7.4 because of the decrease in cellular glycogen content. Vaginal $\mathrm{pH}$ affects the degree of ionization of drugs, which can affect their absorption properties. Physiological changes in the $\mathrm{pH}$ of the vaginal fluids can also result in fluctuations in vaginal bioavailability.

The enzymatic activity in the vaginal epithelium is thought to be lower than in the gastrointestinal tract. The influence of the ovarian cycle on protease activity in the vagina has also been demonstrated. The activity of

\begin{tabular}{lcc}
\hline \multicolumn{3}{l}{ Table 12. Simulated Vaginal Fluid (SVF) } \\
\hline Composition (in water) & SVF1 (g/L) & SVF2 (g/L) \\
\hline sodium chloride & 3.51 & 3.51 \\
\hline potassium hydroxide & 1.40 & 1.40 \\
\hline calcium hydroxide & 0.222 & 0.222 \\
\hline bovine serum albumin (BSA) & 0.018 & 0.018 \\
\hline lactic acid & 2.00 & 2.00 \\
\hline acetic acid & 1.00 & 1.00 \\
\hline glycerol & 0.16 & 0.16 \\
\hline urea & 0.40 & 0.40 \\
\hline glucose & 5.00 & 5.00 \\
\hline mucin & - & $1.5 \%(\mathrm{w} / \mathrm{v})$ \\
\hline Properties & & \\
\hline pH & 4.2 & 4.2 \\
\hline
\end{tabular}

$\beta$-glucuronidase, acid phosphatase, alkaline phosphatase, and esterase all vary in the vaginal tissue of premenopausal and post-menopausal women (1).

Owen and Katz (39) developed a simulated vaginal fluid (SVF1) (Table 12) that models the fluid properties originating in the vagina, specifically the vaginal secretion found in healthy, nonpregnant, premenopausal women.

The volume of vaginal fluid can be measured in two ways, the amount of fluid present at any one time or the amount of fluid produced over an extended time interval. Some studies suggest that the daily production of vaginal fluid is around $6 \mathrm{~g} /$ day, with approximately $0.5-0.75 \mathrm{~g}$ present in the vagina at any one time. A volume of $0.75 \mathrm{~mL}$ of simulated vaginal fluid may be appropriate to evaluate some types of formulations (39).

SVF1 was used to evaluate the in vitro dissolution of polymer-lipid-based mucoadhesive microspheres containing econazole nitrate with the USP Apparatus 1 (basket) in a volume of $900 \mathrm{~mL}$. SVF2 was used to hydrate these microspheres before evaluating their mucoadhesive properties (40).

The in vitro release of clindamycin from bioadhesive gel was performed using $15 \mathrm{~mL}$ of SVF1 in a vertical diffusion cell (41). This dosage form was composed of chitosan, which acts as both bioadhesive and permeation enhancer, and gellan gum, an ion-activated polymer that gels when in contact with ions (i.e., vaginal fluid). A similar evaluation was carried out using SVF1 (10 mL/2 g of product) with poloxamer 407-based vaginal in situ gel containing acyclovir (40).

The swelling behavior, the mucoadhesion, and the in vitro release of nystatin from a mucoadhesive vaginal delivery were evaluated using SVF1 (43). 


\begin{tabular}{ll}
\hline Table 13. Simulated Semen Solution $\mathbf{1}$ & \\
\hline Composition (final volume $100 \mathrm{~mL}$ ) & Amount \\
\hline $\begin{array}{l}0.123 \text { M sodium phosphate monobasic } \\
\text { monohydrate }\end{array}$ & $5.46 \mathrm{~mL}$ \\
\hline $\begin{array}{l}0.123 \mathrm{M} \text { sodium phosphate dibasic } \\
\text { anhydrous }\end{array}$ & $49.14 \mathrm{~mL}$ \\
\hline sodium citrate dihydrate & $813 \mathrm{mg}$ \\
\hline potassium chloride & $90.8 \mathrm{mg}$ \\
\hline potassium hydroxide & $88.1 \mathrm{mg}$ \\
\hline fructose & $272 \mathrm{mg}$ \\
\hline glucose anhydrous & $102 \mathrm{mg}$ \\
\hline lactic acid & $62 \mathrm{mg}$ \\
\hline urea & $45 \mathrm{mg}$ \\
\hline bovine serum albumin & $5.04 \mathrm{~g}$ \\
\hline
\end{tabular}

\section{Simulated Semen (SSe)}

One of the applications of simulated semen is to evaluate its influence in the performance of vaginally applied topical therapeutic, contraceptive, and prophylactic formulations.

Human semen is a mixture of components produced by several different glands. These components are incompletely mixed during ejaculation; hence, the initial ejaculate is not an entirely homogeneous mixture. The prostate is the main source of acid phosphatase, citric acid, inositol, calcium, zinc, and magnesium. The seminal vesicles' contribution is rich in fructose, ascorbic acid, and prostaglandins, while the concentrations of L-carnitine and neutral alpha-glucosidase are indications of epididymal function. The final composition of SSe presented below models the properties of semen (after complete mixture) produced by healthy male donors.

Solution 2: $101 \mathrm{mg}$ of calcium chloride dihydrate in $15.13 \mathrm{~mL}$ of water.

Solution 3: $92 \mathrm{mg}$ of magnesium chloride hexahydrate in $15.13 \mathrm{~mL}$ of water.

\section{Solution 4: $34.4 \mathrm{mg}$ of zinc chloride in $15.13 \mathrm{~mL}$ of} water.

First, add Solution 2, then Solution 3, and finally Solution 4 to Solution 1 (Table 13). The $\mathrm{pH}$ is adjusted to 7.7 with sodium hydroxide. The final solution is sterilized by filtration and can be kept frozen until the moment of use. This simulated semen has a viscosity of about $1.3 \mathrm{CP}$. Its viscosity can be increased to $4 \mathrm{CP}$ by the addition of $0.17 \%$ of methyl cellulose (44).

Data from the literature indicate that the average volume of semen ejaculated is about $3.4 \mathrm{~mL}$. This volume was used to evaluate drug release from vaginal gel formulations (44).

\begin{tabular}{lcc}
\hline \multicolumn{3}{l}{ Table 14. Simulated Tears $\mathbf{1}$ and $\mathbf{2}$} \\
\hline $\begin{array}{l}\text { Composition } \\
\text { (in water) }\end{array}$ & $\begin{array}{c}\text { Simulated Tears 1 } \\
(\mathbf{m g} / \mathbf{m L})\end{array}$ & $\begin{array}{c}\text { Simulated Tears 2 } \\
\text { ( } \mathbf{w} / \mathbf{w})\end{array}$ \\
\hline sodium bicarbonate & 192.4 & $0.2 \%$ \\
\hline potassium chloride & 111 & - \\
\hline calcium chloride & 2.29 & $\begin{array}{c}0.008 \% \\
\left(\mathrm{as} \mathrm{CaCl}_{2} \cdot 2 \mathrm{H}_{2} \mathrm{O}\right)\end{array}$ \\
\hline sodium chloride & 672.8 & $0.67 \%$ \\
\hline albumin & 669 & - \\
\hline glucose & 2.5 & - \\
\hline Properties & & 7.4 \\
\hline pH & 7.4 & \\
\hline
\end{tabular}

\section{OPHTHALMIC ROUTE}

This route is used only for the treatment of local conditions of the eye and cannot be used as a portal of drug entry to the systemic circulation. The $\mathrm{pH}$ of normal tears has a mean value of 7.4 , but there are wide variations. It is lowest on awakening because of acid by-products associated with relatively anaerobic conditions in prolonged lid closure and increases because of loss of carbon dioxide as the eyes open. The tears are more acid in contact-lens wearers because of the impediment of the efflux of carbon dioxide, and more alkaline in diseases such as dry eye, severe ocular rosacea, and lachrymal stenosis. The surface tension of the tear fluid at the eye temperature is $43.6-46.6 \mathrm{mNm}^{-1}$ for normal eyes and $49.6 \mathrm{mNm}^{-1}$ for patients with dry eyes. The osmolality of tears is important, since optical integrity of the cornea is significantly influenced by the tonicity of the tears. The normal osmolality of tears varies from 290 to 310 mOsm $\mathrm{kg}^{-1}$, which is almost equivalent to that of normal saline solution (1). Absorption of drugs into the eye requires good pre-corneal penetration and prolonged contact time with corneal tissues. Ideally, the formulation should sustain drug release and maintain contact with the eye for extended periods of time. The extent of absorption into the eye is severely limited by the physiological constraints such as reflex tearing and blinking. Further, drug loss occurs from tear turnover, solution drainage by gravity, and binding of drugs to proteins and other components of tears. As a result, typically only $1-2 \%$ of the instilled drug is bioavailable (45). The volume of tears in the eye is about $5-10 \mu \mathrm{L}$. The normal secretion is about $1-2 \mu \mathrm{L} / \min (46)$.

Simulated Tears 1 (Table 14) in the volume of $8 \mathrm{~mL}$ was used to evaluate the in vitro release kinetic of poly-anionic oligonucleotide macromolecules from cationic nanoemulsions with potential use for age-related macular degeneration treatment (47). Simulated Tears 2 (Table 14) in the volume of $4 \mathrm{~mL}$ was used to evaluate drug-loading efficiency and in vitro release of pilocarpine from 


\begin{tabular}{lc}
\hline Table 15. Simulated Tears 3 & \\
\hline Composition (in water) & Amount $(\mathrm{mg} / \mathrm{mL})$ \\
\hline lysozyme & 2.68 \\
\hline D-glucose & 6.50 \\
\hline gamma globulin & 1.34 \\
\hline sodium chloride & 6.50 \\
\hline bovine serum albumin & 2.68 \\
\hline $\mathrm{CaCl}_{2} \cdot 2 \mathrm{H}_{2} \mathrm{O}$ & 0.08 \\
\hline Properties & \\
\hline $\mathrm{pH}$ & 7.4 \\
\hline
\end{tabular}

hydrogels. These hydrogels behave as a drug-depot for controlled-release applications (48).The same simulated medium was also used to evaluate the in vitro release of pilocarpine from nanoparticles composed of chitosan and polyacrylic acid (49). Pandit et al. (45) developed in situ forming sodium alginate gels for the extended release of indomethacin to the eye. They evaluated the in vitro gelation using Simulated Tears 2 and Simulated Tears 3 (Table 15) and assessed the in vitro release using Simulated Tears 2 ( $200 \mathrm{~mL} / 2 \mathrm{~mL}$ of sample).

\section{SIMULATED SWEAT (SSW)}

The main composition of human sweat is shown in Table 16. Shimamura et al. (50) prepared several simulated fluids (Table 17) using different proportions of the ions found in human sweat. The numbers in parentheses represents milliequivalents of calcium ions. Each ion concentration and $\mathrm{pH}$ in SSW(3) was adjusted to the median values of the human sweat in Table 16. For SSW(60), SSW(120), and SSW(240), each ion concentration except for calcium was adjusted to the upper limit and the $\mathrm{pH}$ to the lower limit of human sweat.

These simulated media were used to evaluate the in vitro release of nonsteroidal anti-inflammatory drugs from plasters. One of the major problems encountered in

\begin{tabular}{lccc}
\hline Table 16. Main Composition of Human Sweat & \\
\hline Ion & $\begin{array}{c}\text { Concentration } \\
(\mathbf{m E q} / \mathrm{L})\end{array}$ & lon & $\begin{array}{c}\text { Concentration } \\
(\mathbf{m E q} / \mathrm{L})\end{array}$ \\
\hline sodium & $9.7-94.1$ & chloride & $0-65.1$ \\
\hline calcium & $0.2-6$ & phosphorus & $0.003-0.014$ \\
\hline magnesium & $0.03-4$ & sulfur & $0.022-0.231$ \\
\hline iron & $0.022-0.068$ & bromide & $0.002-0.006$ \\
\hline copper & 0.002 & fluoride & $0.011-0.095$ \\
\hline manganese & $0.001-0.003$ & iodine & $0.043-0.096$ \\
\hline zinc & $0.016-0.052$ & potassium & $4.3-10.7$ \\
\hline
\end{tabular}

Table 17. Simulated Sweat

\begin{tabular}{|c|c|c|c|c|}
\hline Salt & $\operatorname{SSW}(3)^{a}$ & $\operatorname{SSW}(60)^{a}$ & $\operatorname{SSW}(120)^{a}$ & $\operatorname{SSW}(240)^{a}$ \\
\hline sodium chloride & 2.92 & 5.49 & 5.49 & 5.49 \\
\hline calcium chloride & 0.166 & 3.32 & 6.64 & 13.28 \\
\hline magnesium sulfate & 0.12 & 0.24 & 0.24 & 0.24 \\
\hline $\begin{array}{l}\text { potassium phosphate } \\
\text { monobasic }\end{array}$ & 1.02 & 1.36 & 1.36 & 1.36 \\
\hline \multicolumn{5}{|l|}{ Properties } \\
\hline $\mathrm{pH}$ & 5.4 & 4.5 & 4.5 & 4.5 \\
\hline
\end{tabular}

${ }^{a}$ The numbers in parentheses indicate milliequivalents of calcium ions.

the in vitro drug-release test using aqueous solution was the swelling of the plaster due to the penetration of water, because the systems studied consisted of water-soluble polymers. Because the swelling of water-soluble polymers is suppressed by some metal ions, especially calcium, and by low $\mathrm{pH}$, the use of simulated sweat with different concentrations of calcium and different $\mathrm{pH}$ was evaluated. As the formulation of plasters varies from manufacturer to manufacturer, SSW of different ionic concentrations is necessary to minimize the swelling. The in vitro release of fentanyl from transdermal systems was evaluated using $500 \mathrm{~mL}$ of SSW(60) using USP Apparatus 5 (paddle over disk) (51).

The British Standard Specification for the Reference Test Method for Release of Nickel from Products Intended to Come into Direct and Prolonged Contact with the Skin (52) has a recommended composition for simulated sweat (SSW2, Table 18), and the recommended volume of simulated fluid is about $1 \mathrm{~mL}$ per $\mathrm{cm}^{2}$ sample area.

Nickel can induce contact sensitization when metallic objects made with nickel alloys are corroded by sweat. The estimation of the allergenic power of these metallic objects is based on an understanding of the electrodissolution mechanism of nickel in sweat. Colin et al. (53) characterized the corrosion layer of copper-nickel alloys in SSW2, with its pH adjusted to 6.5 with ammonia. SSW2 with an adjusted pH of 5 (54), an adjusted pH of 5.5 (55), and with pH values between 4.8 and 5.8 (56) was used to evaluate the corrosion behavior of magnesium alloys used in consumer electronic products. The amount of medium used in most of these studies was about $20 \mathrm{~mL} / \mathrm{cm}^{2}$ of sample area.

\begin{tabular}{lc}
\hline \multicolumn{2}{l}{ Table 18. Simulated Sweat 2 (SSW2) } \\
\hline Compound & Amount (\% in mass) \\
\hline sodium chloride & 0.5 \\
\hline lactic acid & 0.1 \\
\hline urea & 0.1 \\
\hline
\end{tabular}

Dissolution Technologies | AUGUST 2011 
The release of potential allergens from latex gloves was studied using $500 \mathrm{~mL}$ of SSW2 at several pH values, namely, 5, 6, 6.5, 7, 7.2, 7.4, and 8 (57).

\section{CONCLUSION}

Dissolution testing is most often used for the in vitro assessment of the in vivo behavior of a pharmaceutical dosage form, both for development and quality control. Early prediction of the absorption of drug candidates is a key factor in the development of pharmaceutical products. In routine quality control dissolution testing, simple dissolution media like aqueous buffer solutions are preferred because of cost, ease of preparation and recovery, and reproducibility. For development purposes, the use of more complex media, simulating the composition of the biological fluids of the site where the drug product will be administered and/or absorbed, is relevant. These media will subject the pharmaceutical dosage form to conditions that are closer to those encountered in vivo, which can increase the possibility of predicting differences between formulations, provide better understanding of drug-release mechanisms, and allow establishment of in vivo-in vitro correlation (IVIVC).

\section{REFERENCES}

1. Drug Delivery and Targeting for Pharmacists and Pharmaceutical Scientists; Hillery, A. M., Lloyd, A.W., Swarbrick, J., Eds.; Taylor \& Francis: New York, 2001.

2. Kokubo, T.; Ito, S.; Huang, Z. T.; Hayashi, T.; Sakka, S. Ca,P-rich layer formed on high-strength bioactive glass-ceramic A-W.J. Biomed. Mater. Res. 1990, 24 (3), 331-343.

3. Cho, S. B.; Nakanishi, K.; Kokubo, T.; Soga, N.; Ohtsuki, C.; Nakamura, T. Apatite formation on silica gel in simulated body fluid: its dependence on structures of silica gels prepared in different media.J.Biomed.Mater. Res. 1996, 33 (3), 145-151.

4. Cho, S. B.; Nakanishi, K.; Kokubo, T.; Soga, N.; Ohtsuki, C.; Nakamura, T.; Kitsugi, T.; Yamamuro, T. Dependence of apatite formation on silica gel on its structure: effect of heat treatment.J.Am. Ceram. Soc. 1995, 78 (7), 1769-1774.

5. Kokubo, T.; Takadama, H. How useful is SBF in predicting in vivo bone bioactivity? Biomaterials 2006, 27 (15), 2907-2915.

6. Conzone, S. D.; Brown, R. F; Day, D. E.; Ehrhardt, G. J. In vitro and in vivo dissolution behavior of a dysprosium lithium borate glass designed for the radiation synovectomy treatment of rheumatoid arthritis. J. Biomed. Mater. Res. 2002, 60 (2), 260-268.

7. Conzone, S. D.; Hemrick, J. G.; Day, D. E. Glass formation and chemical durability of dysprosium lithium borate glasses intended for in vivo radiation synovectomy. Glass Sci. Technol. 2001, 74 (2), 39-45.

8. Malafaya, P. B.; Reis, R. L. Bilayered chitosan-based scaffolds for osteochondral tissue engineering: influence of hydroxyapatite on in vitro cytotoxicity and dynamic bioactivity studies in a specific double-chamber bioreactor. Acta Biomater. 2009, 5 (2), 644-660.

9. Söderlind, E.; Dressman, J. B. Physiological Factors Affecting Drug Release and Absorption in the Gastrointestinal Tract. In Oral Drug Absorption: Prediction and Assement, 2nd ed.; Dressman, J. B., Reppas, C., Eds.; Drugs and the Pharmaceutical Sciences Vol. 193; Informa Healthcare USA, Inc.: New York, 2010; pp 1-20.

10. Müllertz, A. Food Effects on Drug Absorption and Dosage Form Performance. In Oral Drug Absorption: Prediction and Assessment, 2nd ed.; Dressman, J. B. Reppas, C., Eds.; Drugs and the Pharmaceutical Sciences Vol. 193; Informa Healthcare USA, Inc.: New York, 2010; pp 90-107.

11. Vertzoni, M.; Dressman, J.; Butler, J.; Hempenstall, J.; Reppas, C. Simulation of fasting gastric conditions and its importance for the in vivo dissolution of lipophilic compounds. Eur.J. Pharm. Biopharm. 2005, 60,413-417.

12. Klein, S.; Butler, J.; Hempenstall, J. M,; Reppas, C.; Dressman, J.B. Media to simulate the postprandial stomach I. Matching the physicochemical characteristics of standard breakfasts. J. Pharm. Pharmacol. 2004, 56 (5), 605-610.

13. Jantratid, E.; Janssen, N.; Reppas, C.; Dressman, J. B. Dissolution media simulating conditions in the proximal human gastrointestinal tract: an update. Pharm. Res. 2008, 25 (7), 1663-1676.

14. Jantratid, E.; Dressman, J. Biorelevant Dissolution Media Simulating the Proximal Human Gastrointestinal Tract: An Update. Dissolution Technol. 2009, 16 (3), 21-25.

15. Klein, S. Generation of Biorelevant Media Profiles for Prediction of Food Effects on Release from MR Dosage Forms. Dissolution Technol. 2009, 16 (3), 39-40.

16. Boni, J. E.; Brickl, R. S.; Dressman, J.; Pfefferle, M.L. Instant FaSSIF and FeSSIF-Biorelevance Meets Practicality. Dissolution Technol. 2009, 16 (3), 41-45.

17. Kataoka, M.; Masaoka, Y.; Sakuma, S.; Yamashita, S. Effect of food intake on the oral absorption of poorly water-soluble drugs: in vitro assessment of drug dissolution and permeation assay system. J. Pharm. Sci. 2006, 95 (9), 2051-2061.

18. Patel, N.; Forbes, B.; Eskola, S.; Murray, J. Use of simulated intestinal fluids with $\mathrm{Caco} 2$ cells and rat ileum. Drug Dev. Ind. Pharm. 2006, 32, 151-161.

19. Chen, L.; Li, X.; Pang, Y.; Lin, L.; Zhang, X.; Yu, L. Resistant starch as a carrier for oral colon-targeting drug matrix system. J. Mater. Sci. Mater. Med. 2007, 18, 2199-2203.

20. Abrahanm, S.; Srinath, M. S. Development of modified pulsincap drug delivery system of metronidazole for drug targeting. Indian J. Pharm. Sci. 2007, 69 (1), 24-27.

21. Aswar, P. B.; Khadabadi, S. S.; Kuchekar, B. S.;Wane, T.P.; Matake, N. Development and in vitro evaluation of 
colon-specific formulations for orally administered diclofenac sodium. Arch. Pharm. Sci. Res. 2009, 1 (1), 48-53.

22. Chang, C.;Wang, Z. C.; Quan, C.Y.; Cheng, H.; Cheng, S.X.; Zhang, X.Z.; Zhuo, R. X. Fabrication of a novel $\mathrm{pH}$-sensitive glutaraldehyde cross-linked pectin nanogel for drug delivery. J. Biomat. Sci.-Polym. E. 2007, 18 (12), 1591-1599.

23. Fotaki, N.; Symillides, M.; Reppas, C. In vitro versus canine data for predicting input profiles of isosorbide-5-monohydrate from oral extended release products on a confidence interval basis. Eur.J. Pharm. Sci. 2005, 24, 115-122.

24. Vertzoni, M.; Diakidou, A.; Chatzilias, M.; Soderlind, E.; Abrahamsson, B.; Dressman, J. B.; Reppas, C. Biorelevant media to simulate fluids in the ascending colon of humans and their usefulness in predicting intracolonic drug solubility. Pharm. Res. 2010, 27, 2187-2196.

25. Davis, R. E.; Hartman, C.W.; Fincher, J. H. Dialysis of ephedrine and pentobarbital from whole human saliva and simulated saliva.J. Pharm. Sci. 1971,60 (3), 429-432.

26. Azarmi, S.; Roa, W.; Loebenberg, R. Current perspectives in dissolution testing of conventional and novel dosage forms. Int. J. Pharm. 2007, 328, 12-21.

27. Duffo, G. S.; Castillo EQ Development of an artificial saliva solution for studying the corrosion behavior of dental alloys. Corrosion 2004, 6, 594-602.

28. Kartal, A.; Marvola, J.; Matheka, J.; Peltoniemi, M.; Siven, M. Computational prediction of local drug effect on carcinogenic acetaldehyde in the mouth based on in vitro/in vivo results of freely soluble L-cysteine. Drug Dev. Ind. Pharm. 2010, 36 (6), 715-723.

29. Tavss, E. A.; Gaffar, A.; King, W. J. Studies on the formation of electrostatic complexes between benzethonium chloride and anionic polymers. J. Pharm. Sci. 1984, 73 (8), 1148-1152.

30. Mashru, R. C.; Sutariya, V. B.; Sankalia, M. G.; Parikh, P.P. Development and evaluation of fast-dissolving film of salbutamol sulphate. Drug. Dev. Ind. Pharm. 2005, 31, 25-34.

31. Gohel, M. C.; Parikh, R. K.; Aghara, P.Y.; Nagori, S. A.; Delvadia, R. R.; Dabhi, M. Application of simplex lattice design and desirability function for the formulation development of mouth dissolving film of salbutamol sulphate. Curr. Drug Deliv. 2009, 6 (5), 486-494.

32. Colombo, C.; Monhemius, A. J.; Plant, J. A. Platinum, palladium and rhodium release from vehicle exhaust catalysts and road dust exposed to simulated lung fluids. Ecotox. Environ. Safe. 2008, 71, 722-730.

33. Gray, J. E.; Plumlee, G. S.; Morman, S. A.; Higueras, P.L.; Crock, J. G.; Lowers, H. A.; Witten, M. L. In Vitro Studies Evaluating Leaching of Mercury from Mine Waste Calcine using Simulated Human Body Fluids. Environ. Sci.Technol. 2010, 44 (12), 4782-4788.

34. Moss, O. R. Simulants of lung interstitial fluid. Health Phys. 1979, 36 (3), 447-448.
35. Ungaro, F.; Bianca, R. E. V.; Giovino, C.; Miro, A.; Sorrentino, R.; Quaglia, F.; Rotonda, M. I. Insulin-loaded PLGA/cyclodextrin large porous particles with improved aerosolization properties: in vivo deposition and hypoglycaemic activity after delivery to rat lungs. J. Controlled Release 2009, 135 (1), 25-34.

36. Son, Y. J.; McConville, J.T. Development of a standardized dissolution test method for inhaled pharmaceutical formulations. Int. J. Pharm. 2009, 382, 15-22.

37. Yang,W.;Tam, J.; Miller, D. A.; Zhou, J.; McConville, J.T.; Johnston, K. P.; Williams III, R. O. High bioavailability from nebulized itraconazole nanoparticle dispersions with biocompatible stabilizers. Int.J. Pharm. 2008, 361, 177-188.

38. Cheng, Y. S.; Dahl, A. R.; Jow, H. N. Dissolution of Metal Tritides in a Simulated Lung Fluid. Health Phys. 1997, 73 (4), 633-638.

39. Owen, D.H.; Katz, D. F. A vaginal fluid stimulant. Contraception 1999, 59 (2), 91-95.

40. Albertini, B.; Passerini, N.; Sabatino, M.; Vitali, B.; Brigidi, P.; Rodriguez, L. Polymer-lipid based mucoadhesive microspheres prepared by spray-congealing for the vaginal delivery of econazole nitrate. Eur. J. Pharm. Sci. 2009, 36, 591-601.

41. Gupta, H.; Sharma, A. Ion activated bioadhesive in situ gel of clindamycin for vaginal application. Int. J. Drug Deliv. 2009, 1 (1), 32-40.

42. Liu, Y.; Zhu, Y.Y.;Wei, G.; Lu, W.Y. Effect of carrageenan on poloxamer-based in situ gel for vaginal use: improved in vitro and in vivo sustained-release properties. Eur.J. Pharm. Sci. 2009, 37, 306-312.

43. Hombach, J.; Palmberger, T. F.; Bernkop-Schnurch, A. Development and in vitro evaluation of a mucoadhesive vaginal delivery system for nystatin. J. Pharm. Sci. 2009, 98 (2), 555-564.

44. Owen, D. H.; Katz, D. F. A Review of the Physical and Chemical Properties of Human Semen and the Formulation of a Semen Stimulant. J. Androl. 2005, 26 (4), 459-469.

45. Pandit, J. K.; Bharathi, D.; Srinatha, A.; Ridhurkar, D. N.; Singh, S. Long acting ophthalmic formulation of indomethacin: evaluation of alginate gel systems. Indian J. Pharm. Sci. 2007, 69 (1), 37-40.

46. van Haeringen, N. J. Clinical Biochemistry of Tears. Surv. Ophthalmol. 1981, 26 (2), 84-96.

47. Hagigit, T.; Nassar, T.; Behar-Cohen, F.; Lambert, G.; Benita, $S$. The influence of cationic lipid type on in-vitro release kinetic profiles of antisense oligonucleotide from cationic nanoemulsions. Eur. J. Pharm. Biopharm. 2008, 70, 248-259.

48. Anumolu, S. S.; Singh, Y.; Gao, D.; Stein, S.; Sinko, P. J.Design and evaluation of novel fast forming pilocarpine-loaded ocular hydrogels for sustained pharmacological response. J. Controlled Release 2009, 137, 152-159.

49. Lin, H. R.; Yu, S. P.; Lin, Y. J.; Wang, T. S. High pH tolerance of a chitosan-PAA nanosuspension for ophthalmic delivery of pilocarpine. J. Biomat. Sci.-Polym. Ed. 2010, 21, 141-157. 
50. Shimamura, T.; Tairabune, T.; Kogo, T.; Ueda, H.; Numajiri, S.; Kobayashi, D.; Morimoto, Y. Investigation of the release test method for the topical application of pharmaceutical preparations: release test of cataplasma including nonsteroidal anti-inflammatory drugs using artifical sweat. Chem. Pharm. Bull. 2004, 52 (2), 167-171.

51. Numata, C.; Teraoka, R.; Matsuda, Y.; Yagi, K.; Hirai, M.; Kitagawa, S. Dose control study on fentanyl patch using two types of covering material.Jpn. J.Pharm. Health Care Sci. 2008, 34 (1), 26-31.

52. British Standard Specification for the Reference test method for release of nickel from products intended to come into direct and prolonged contact with the skin; BS EN 1811:1999; British Standards Institution: London, 1999.

53. Colin, S.; Krier, G.; Jolibois, H.; Hachimi, A.; Muller, J. F.; Chambaudet, A. Characterization of the corrosion layer of copper-nickel alloys in a synthetic sweat medium by FTMS and LAMMA laser. Appl. Surf. Sci. 1998, 125, 29-45.

54. Song, Y.W.; Shan, D. Y.; Han, E. H. Corrosion behaviors of electroless plating Ni-P coatings deposited on magnesium alloys in artificial sweat solution. Electrochim. Acta 2007, 53 (4), 2009-2015.

55. Zhang, S.;Wu, F. Ellipsometric analysis of corrosion behavior of $3 \mathrm{C}$ magnesium alloy surface touched by simulated sweat. Surf. Interface Anal. 2011, 43, 752-756.

56. Wu, F.; Zhang, S.;Tao, Z. Corrosion behavior of $3 C$ magnesium alloys in simulated sweat solution. Mater. Corros. 2011, 62 (3), 234-239.

57. Abraham, E. K.; Ramesh, P.; Joseph, R.; Mohanan, P.V.; Remakumari, V.M. Release of dithiocarbamates into sweat from natural rubber latex surgical gloves. J. Appl. Polym. Sci. 2006, 102 (3), 2055-2061. 